\title{
Adult attachment and approaches to activity engagement in chronic pain
}

\author{
Nicole E Andrews BOccThy Hon ${ }^{1,2,3}$, Pamela J Meredith $\mathrm{PhD}^{1}$, \\ Jenny Strong PhD ${ }^{1}$, Genevieve F Donohue BOccThy Hon ${ }^{1}$
}

NE Andrews, PJ Meredith, J Strong, GF Donohue. Adult attachment and approaches to activity engagement in chronic pain. Pain Res Manag 2014;19(6):317-327.

BACKGROUND: The way in which individuals with chronic pain habitually approach activity engagement has been shown to impact daily functioning, with both avoidance of one's daily activities and overactivity (activity engagement that significantly exacerbates pain) associated with more pain, higher levels of physical disability and poorer psychological functioning.

OBJECTIVE: To provide insight into the development of maladaptive habitual approaches to activity engagement in chronic pain by applying an attachment theory framework.

METHODS: A sample of 164 adults with chronic pain completed selfreport measures of attachment, approach to activity and pain cognitions. Mediation analyses were undertaken to examine the direct association between attachment variables and maladaptive approaches to activity, and to test for the mediating role of pain cognitions (catastrophizing and thought suppression).

RESULTS: Results demonstrated that higher levels of secure attachment were associated with lower levels of activity avoidance, which was fully mediated by lower levels of pain catastrophizing; higher levels of preoccupied or fearful attachment were directly associated with higher levels overactivity; higher levels of preoccupied attachment were associated with higher levels of activity avoidance, which was partially mediated by higher levels of pain catastrophizing; and higher levels of fearful attachment were indirectly associated with higher levels of activity avoidance through higher levels of catastrophizing.

CONCLUSIONS: These results provide preliminary support for the suggestion that insecure attachment may be a source of vulnerability to the development of disabling activity patterns in chronic pain.

Key Words: Activity avoidance; Adult attachment; Catastrophizing; Chronic pain; Overactivity; Thought suppression

$T_{\mathrm{e}, \mathrm{m}}^{\mathrm{w}}$ wo nonoptimal approaches to activity adopted by individuals experiencing persistent pain are described in the chronic pain literature: overactivity and activity avoidance. The first refers to engagement in excessive amounts of activity that results in significant increases in pain and periods during which the individual is unable to function. The second describes a subgroup of patients who reduce their engagement in physical or other daily activities as a means to minimize pain escalation $(1,2)$. It is accepted clinically that overactivity or activity avoidance behaviour adversely affect an individual's daily functioning. Activity pacing, a treatment strategy used to alter overactivity and avoidance behaviour, is considered to be an essential element of pain management programs and is one of the most widely endorsed pain management strategies $(3,4)$. In addition, results of a systematic review suggest that higher levels of selfreported activity avoidance or overactivity are associated with increased pain, poorer psychological functioning and more physical disability (5). As such, both activity avoidance and overactivity may

\section{L'attachement des adultes et leur attitude envers l'activité physique en cas de douleur chronique}

\begin{abstract}
HISTORIQUE : L'attitude habituelle des personnes souffrant de douleur chronique envers l'activité physique influe sur leur fonctionnement quotidien. L'évitement des activités quotidiennes et l'activité excessive (qui exacerbent considérablement la douleur) s'associent parfois tous deux à plus de douleur, à un taux plus élevé d'invalidité physique et à un fonctionnement psychologique plus négatif.
\end{abstract}

OBJECTIF : Donner un aperçu de l'acquisition d'une attitude mésadaptée envers l'activité en cas de douleur chronique, selon la théorie de l'attachement.

MÉTHODOLOGIE : Un échantillon de 164 adultes atteints de douleur chronique ont transmis leurs mesures autodéclarées d'attachement, d'attitude envers l'activité et de cognitions de la douleur. Des analyses de médiation ont été entreprises pour examiner l'association directe entre les variables liées à l'attachement et les attitudes mésadaptées envers l'activité, ainsi que pour vérifier le rôle médiateur des cognitions de la douleur (catastrophisation et suppression de la pensée).

RÉSULTATS : Les résultats ont démontré que des taux plus élevés d'attachement solide s'associent à un taux plus faible d'évitement de l'activité, entièrement médiés par des taux plus faibles de catastrophisation de la douleur. Des taux plus élevés d'attachement de type préoccupé ou craintif s'associent directement à des taux plus élevés de suractivité, tandis que des taux plus élevés d'attachement de type préoccupé s'associent à des taux plus élevés d'évitement de l'activité, médiés partiellement par des taux plus élevés de catastrophisation de la douleur. Enfin, des taux plus élevés d'attachement de type craintif s'associaient indirectement à des taux plus élevés d'évitement de l'activité, en raison de taux plus élevés de catastrophisation.

CONCLUSIONS : À première vue, ces résultats appuient la suggestion selon laquelle un attachement fragile peut favoriser l'acquisition de profils d'activité invalidants en cas de douleur chronique.

be conceptualized as 'maladaptive approaches' to activity engagement for individuals in pain.

Factors that contribute to the development of such maladaptive approaches have been a topic of speculation and inquiry. Catastrophizing thoughts about pain have long been considered to lead to avoidance of activity (6), with several authors linking catastrophizing to self-reported activity avoidance in clinical samples (7-11). In contrast, suppressing thoughts about pain has recently been theorized to contribute to overactivity (12), and evidence supporting this link is mounting $(13,14)$. It has been suggested that overactivity is inherent to a person's personality $(15,16)$, with these individuals engaging in high levels of work and productive tasks before the development of chronic pain (16). Overactivity is also believed to contribute to the development of avoidance behaviour. A combination of overactivity and activity avoidance manifesting in the same individual with chronic pain has been documented by clinicians $(1,17)$. These observations suggest that some individuals who initially

${ }^{1}$ Division of Occupational Therapy, School of Health and Rehabilitation Sciences, The University of Queensland; ${ }^{2}$ Department of Occupational

Therapy; ${ }^{3}$ The Professor Tess Cramond Multidisciplinary Pain Centre, The Royal Brisbane and Women's Hospital, Brisbane, Australia

Correspondence: Ms Nicole E Andrews, Department of Occupational Therapy, Level 2 James Mayne Building, The Royal Brisbane and Women's

Hospital, Herston, Queensland, Australia 4029. Telephone 61-7-3646-8111, fax 61-7-3646-7495, e-mail nicole.andrews@uqconnect.edu.au

OPEN $\bigcirc$ ACCESS

This open-access article is distributed under the terms of the Creative Commons Attribution Non-Commercial License (CC BY-NC) (http:// creativecommons.org/licenses/by-nc/4.0/), which permits reuse, distribution and reproduction of the article, provided that the original work is properly cited and the reuse is restricted to noncommercial purposes. For commercial reuse, contact support@pulsus.com 
engage in overactivity begin to avoid certain pain-provoking activities as pain exacerbations secondary to overactivity become more severe and prolonged over time.

The objective of the present study was to provide further insight into the development of maladaptive approaches to activity engagement in chronic pain. In doing so, an attachment theory framework $(18-20)$ was applied to examine the notion that some individuals are inherently more likely to develop maladaptive approaches to activity. In addition, previous empirical investigations (studies that link catastrophizing to activity avoidance and thought suppression to overactivity) are extended by defining and investigating the role of cognitions in the development of overactivity and activity avoidance behaviour.

\section{Adult attachment and working models}

Derived from the disciplines of ethology and evolution, Bowlby's attachment theory (18-20) and its application have offered fundamental insights into the development of various emotional, cognitive, motivational and behavioural tendencies that constitute personality (21). Bowlby believed that, during early interactions in infancy, children develop internal mental representations about the self, significant others and the larger social world. These representations influence attachment behaviour (efforts to achieve physical or psychological closeness with attachment figures), guiding cognition, affect and behaviour in future interactions. Bowlby termed these representations 'internal working models' of attachment and maintained that fairly consistent patterns of caregiving throughout childhood and adolescence serve to structure, strengthen and solidify working models, rendering them resistant to change. Longitudinal studies have shown that working models can remain relatively stable across the lifespan (22-24). Thus, once formed, working models can become core features of personality that continue to shape social perception and behaviour in close relationships into adulthood (25).

In adults, working models of attachment can be assessed using selfreport measures. Using these measures, attachment orientations have been consistently shown to have two underlying dimensions: discomfort with closeness (avoidant attachment) and relationship anxiety (anxious attachment) (26-28). Three insecure attachment styles can be defined using these two dimensions: dismissing (high avoidance, low anxiety), preoccupied (high anxiety, low avoidance), and fearful (high avoidance and high anxiety) (26). Secure attachment denotes individuals low in both attachment anxiety and avoidance (26).

Following the integration of a large volume of research, Mikulincer and Shaver (21) proposed a control systems model to characterize the activation and operation of the attachment system in adulthood. In accordance with this model, the attachment system is activated by the presence of an actual threat or the perception that unfolding events will impact negatively on an individual's well-being, adjustment or survival. Securely attached individuals hold internalized representations of available, comforting attachment figures resulting in a sense of felt security, proximity seeking and constructive coping when a threat is encountered. In contrast, insecurely attached individuals tend to either deactivate or hyperactivate the attachment system in an attempt to cope with threats. Preoccupied attachment is associated with hyperactivation strategies, which consist of overdependence on others for comfort; attempts to minimize cognitive, emotional and physical distance from others; and excessive demands for attention and care $(21,29)$. Deactivation strategies, characterized by denial of attachment needs, avoidance of emotional states that may trigger the attachment system and compulsive self-reliance, are associated with dismissing attachment $(21,29)$. Fearful attachment represents a combination of distrust in other's responsiveness and negative self-perceptions. This is believed to result in coping similar to that of dismissing attachment in which individuals avoid close relationships and distance themselves from others due to a heightened fear of rejection $(21,25)$. However, unlike dismissing attachment, these individuals experience ongoing anxiety and a desire for love and support, which may result in a haphazard, chaotic utilization of both hyperactivating and deactivating strategies $(21,30)$.

\section{Attachment and engagement in work and productive tasks}

While there is currently no evidence of associations between attachment working models and activity engagement following any disease pathogenesis, let alone chronic pain, van Houdenhove (16) suggested that individuals with chronic pain who engage in overactivity have a history of high levels of work and productive task engagement before the development of their chronic pain. In the 1990s, Hazan and Shaver (31) proposed that attachment orientations in adulthood may be related to work and productive task engagement. They theorized that avoidantly attached adults (dismissing and fearful individuals) use work as a means of avoiding uncomfortable interactions with others and anxiety associated with unmet attachment needs. Because work serves to reduce anxiety, they proposed that these individuals are reluctant to stop working and take vacations. In contrast, anxiously attached adults (preoccupied and fearful individuals) were believed to use work as a means to attract attention and approval from others. As a result, it was predicted that these individuals may have a tendency to become overly obligated at work.

Consistent with these expectations, empirical evidence has provided support for links between avoidant attachment and prioritizing work over relationships; acknowledging that work interferes with relationships and social activities; being dissatisfied with work hours; being less likely to take pleasurable holidays; and feeling nervous when not working $(31,32)$. In addition, higher levels of fearful and preoccupied attachment have been associated with higher levels of overcommitment to work (33). Both anxious and avoidant attachment have consistently been linked to maladaptive perfectionism (34-37); Pines (38) found that individuals with higher levels of burnout also reported higher levels of attachment avoidance or anxiety. Taken together, these results suggest that individuals with an insecure attachment pattern may be more likely than securely attached individuals to engage in high levels of work and productive tasks before the onset of a disease.

\section{Attachment and maladaptive responses to chronic pain}

Attachment-based theoretical perspectives of pain began to emerge in the 1980s and early 1990s. Theorists contended that the pain experience is a form of threat that activates the attachment system. This leads to a cascade of behaviours that place insecurely attached individuals at greater risk for developing chronic pain and of being less able to cope with chronic pain once it is established (39-41). Empirical investigation of these assertions followed.

Insecure attachment patterns have been found to be more prominent in chronic pain samples $(42,43)$ compared with samples taken from the wider community $(42,44,45)$. Attachment insecurity has also been associated with indicators of poorer functioning in chronic pain samples such as higher levels of disability $(42,46,47)$, poorer mental health $(48,49)$ and higher opioid use $(48)$. In addition, numerous studies have explored links between attachment and differences in coping with pain including pain appraisals, support seeking and affect regulation, with results supporting Mikulincer and Shaver's (21) control systems model (reviewed in Meredith et al [50]). Insecure attachment has not been linked directly to either avoidance of activity or overactivity. However, attachment has been linked with the cognitive processes considered to contribute to the development of these approaches. Both preoccupied and fearful attachment have been associated with higher levels of pain catastrophizing (51-53) while secure attachment has been linked to lower levels of pain catastrophizing $(43,52)$. In addition, dismissing attachment has been linked to thought suppression and masking pain from others (54). The associations observed in previous studies between cognitions and both attachment and approach to activity engagement raise the possibility that a relationship between attachment and approach to activity engagement exists, and that cognitions may mediate this relationship. That is, attachment may influence cognitions which, in turn, affects approach to activity engagement in chronic pain. 
The present study

Both avoidance of one's daily activities and engagement in overactivity have been associated with indicators of poorer functioning in chronic pain including increased pain, poorer mental health and more physical disability (5). Developing a better understanding of how avoidance and overactivity behaviour develops would lead to improvements in treatment options aimed at preventing and altering these behaviours. Collectively, the current evidence suggests that insecure attachment may be associated with the development of overactivity and activity avoidance in chronic pain. Thus, the aims of the present exploratory study were: to establish links between adult attachment and habitual approaches to activity engagement in a chronic pain sample, and to investigate the mediating role of catastrophizing and thought suppression. Because all constructs under investigation have been associated with pain and disability $(5,13,50,55)$, disability and pain intensity were controlled for in these investigations.

Tentative hypotheses were formulated based on aforementioned information:

Hypothesis 1: Higher levels of secure attachment will be associated with lower levels of catastrophizing and activity avoidance. The relationship between secure attachment and activity avoidance will be mediated by catastrophizing.

Hypothesis 2: Higher levels of preoccupied attachment will be associated with higher levels of catastrophizing, activity avoidance and overactivity. The relationship between preoccupied attachment and activity avoidance will be mediated by catastrophizing.

Hypothesis 3: Higher levels of dismissing attachment will be associated with higher levels of thought suppression and overactivity. The relationship between dismissing attachment and overactivity will be mediated by thought suppression.

Hypothesis 4: Higher levels of fearful attachment will be associated with higher levels of catastrophizing, activity avoidance and overactivity. The relationship between preoccupied attachment and activity avoidance will be mediated by catastrophizing.

\section{METHODS}

Participants

A total of 171 adults receiving treatment at a multidisciplinary pain centre in a major metropolitan tertiary hospital in Australia were invited to participate in the study. Seven patients declined the invitation, resulting in a total of 164 (96\%) participants. Participants were all experiencing chronic non-cancer-related pain ( $>3$ months duration) and were $\geq 18$ years of age. Demographic details of the sample are presented in Tables 1 and 2. Participants were mostly married, unemployed due to pain and reported multiple pain sites. Lower back pain was the most common pain complaint (73.2\%). Participants had a mean $( \pm \mathrm{SD})$ age of $52.3 \pm 12$ years and a mean duration of pain of $11.9 \pm 10.8$ years. Of the 164 participants, 126 reported a strong preference for one attachment style. Responses taken from these 126 participants indicated that a dismissing attachment style was the most common preference $(38.9 \%)$, followed by secure $(34.9 \%)$, and then fearful $(17.5 \%)$ and preoccupied $(17.5 \%)$. Data from all 164 participants were used in analyses.

\section{Protocol}

The Royal Brisbane and Women's Hospital's Human Research Ethic Committee (Number: HREC/09/QRBW/365) (Brisbane, Australia) and The University of Queensland's Behavioral and Social Sciences Ethical Review Committee (Number: 2010000501) (Brisbane, Australia) approved the protocol for the present study. Patients were invited to participate in the study during a hospital appointment. Participants were provided with an information sheet and were required to provide written informed consent. Participants completed a set of written questionnaires investigating attachment style, pain cognitions, approach to activity engagement, disability, pain intensity and demographic data. Participation was voluntary and no incentive was provided.
TABLE 1

Descriptive data of categorical demographic variables $(n=164)$

\begin{tabular}{|c|c|}
\hline Variable & n (\%) \\
\hline \multicolumn{2}{|l|}{ Sex } \\
\hline Female & $86(52.44)$ \\
\hline Male & $78(47.56)$ \\
\hline \multicolumn{2}{|l|}{ Relationship status } \\
\hline Single & $26(15.85)$ \\
\hline Defacto or in a stable relationship & $17(10.37)$ \\
\hline Married & $81(49.39)$ \\
\hline Separated & $11(6.71)$ \\
\hline Divorced & $23(14.02)$ \\
\hline Widowed & $6(3.66)$ \\
\hline \multicolumn{2}{|l|}{ Education level } \\
\hline Primary school & $12(7.32)$ \\
\hline Junior high school certificate & $56(34.15)$ \\
\hline Senior high school certificate & $33(20.12)$ \\
\hline Tertiary university & $41(25.00)$ \\
\hline Tertiary nonuniversity & $22(13.41)$ \\
\hline \multicolumn{2}{|l|}{ Employment } \\
\hline Employed full-time & $12(7.32)$ \\
\hline Employed part-time & $12(7.32)$ \\
\hline Home duties & $12(7.32)$ \\
\hline Retired & $36(21.95)$ \\
\hline Unemployed due to pain & $86(52.44)$ \\
\hline Unemployed due to other reasons & $6(3.66)$ \\
\hline \multicolumn{2}{|l|}{ Pain location } \\
\hline Head and face & $27(16.46)$ \\
\hline Shoulder/upper limb & $73(44.51)$ \\
\hline Lower back & $120(73.17)$ \\
\hline Abdomen/groin & $39(23.78)$ \\
\hline Thigh & $52(31.71)$ \\
\hline Calf/ankle/feet & $73(44.51)$ \\
\hline Neck & $62(37.80)$ \\
\hline Upper back & $42(25.61)$ \\
\hline Chest & $23(14.02)$ \\
\hline Buttocks & $42(25.61)$ \\
\hline Knees & $51(31.10)$ \\
\hline Total body pain & $6(3.66)$ \\
\hline \multicolumn{2}{|l|}{ Relationship Questionnaire - Attachment } \\
\hline Secure & $44(34.92)$ \\
\hline Fearful & $22(17.46)$ \\
\hline Preoccupied & $11(8.73)$ \\
\hline Dismissing & $49(38.89)$ \\
\hline
\end{tabular}

\section{Measures}

Demographic data: Participants' age, sex, level of education, employment status, and pain location and duration were recorded.

The Relationship Questionnaire: Because conceptualizing attachment as a prototypical construct is generally preferred in the clinical setting $(29,56)$, a prototypical measure of attachment was chosen for the present study in preference to a dimensional measure. The Relationship Questionnaire (26) provides a self-report measure of adult attachment relating to close peer relationships. The measure contains four statements reflecting the four prototypical attachment styles described in Bartholomew and Horowitz's (26) four-category model (secure, dismissing, preoccupied and fearful). Participants are asked to select the paragraph that best represents their attachment style. In addition, they rate their resemblance to each attachment style on a scale of 1 to $7(1=$ 'not at all like me', to 7 = 'very much like me'), thereby allowing for both a continuous and categorical measure 
TABLE 2

Descriptive data for continuous variables $(n=164)$

\begin{tabular}{lccc}
\hline Variable & $\mathbf{n}$ & Mean \pm SD & Range \\
\hline Chronicity, years & 161 & $11.89 \pm 10.84$ & $0.58-52$ \\
Age, years & 164 & $52.30 \pm 11.98$ & $20-81$ \\
Number of pain sites & 158 & $3.97 \pm 2.48$ & $1-14$ \\
RQ Secure Attachment & 158 & $3.93 \pm 2.04$ & $1-7$ \\
RQ Fearful Attachment & 160 & $3.27 \pm 2.07$ & $1-7$ \\
RQ Preoccupied Attachment & 159 & $2.81 \pm 1.90$ & $1-7$ \\
RQ Dismissing Attachment & 161 & $4.28 \pm 2.07$ & $1-7$ \\
PARQ Avoidance & 157 & $25.25 \pm 7.49$ & $5-40$ \\
PARQ Confrontation & 157 & $22.74 \pm 6.15$ & $2-30$ \\
AEQ Thought Suppression & 158 & $11.84 \pm 6.72$ & $0-24$ \\
PCS Catastrophizing & 161 & $23.05 \pm 13.15$ & $0-50.5$ \\
ODI Pain Intensity & 164 & $2.34 \pm 0.99$ & $0-5$ \\
ODI Pain-related Disability & 163 & $46.75 \pm 14.18$ & $10-78$ \\
\hline
\end{tabular}

AEQ Avoidance-Endurance Questionnaire; ODI Oswestry Disability Index; $P A R Q$ Pain and Activity Relations Questionnaire; PCS Pain Catastrophizing Scale; $R Q$ Relationship Questionnaire

of the four attachment styles. Only the continuous measure was used in the analyses of the present study because research has shown that individual differences in attachment are quantitatively distributed and that the categorization of attachment results in a reduction of statistical power (57). As suggested by Bartholomew (58), participants completed the forced-choice paragraph to minimize order effects when ranking each prototype and the categorical measure was used to describe the sample. The Relationship Questionnaire is a measure frequently used to assess adult attachment style, and has adequate reliability and validity (59-61).

The Pain and Activity Relations Questionnaire: The Pain and Activity Relations Questionnaire (PARQ) (62) includes 21 items divided into three subscales: avoidance, confrontation and pacing. The confronting subscale provides a measure of overactivity while the avoidance subscale provides a measure of avoidance of activity. Participants rate the frequency with which they engage in certain behaviours on a six-point Likert scale $(0=$ never, to $5=$ always $)$. The internal consistency and validity of the confronting and avoidance subscales of the questionnaire is adequate, based on initial psychometric testing by the authors (62). The authors established validity through a factor analysis and examining the correlations between the scales and measures of physical activity (ie, avoidance subscale of the Pain Anxiety Symptoms Scale [9], patients' estimated average daily uptime, and physical disability composite score from the Sickness Impact Profile [63]). The avoidance subscale was negatively associated with uptime and positively associated with physical disability and the avoidance subscale of the Pain Anxiety Symptoms Scale. The confronting subscale was not significantly associated with the measures of physical activity. The pacing subscale was not used in the current study due to confusion in the literature regarding whether self-report measures of pacing reflect quota-contingent pacing, as taught in chronic pain programs, or pain-contingent pacing, which may be maladaptive $(5,64)$. Validity testing by the PARQ authors showed that the pacing subscale was positively correlated with avoidance $(\mathrm{r}=0.51)$ and physical disability $(\mathrm{r}=0.23)$, which is in contrast to theory. Sample items of the scales used include: 'I avoid activities that cause pain' (avoidance), and 'I spend too much time on some activities and experience increased pain later' (confronting). Internal consistency ratings for these scales in the current study were 0.77 (confronting) and 0.82 (avoidance).

The Pain Catastrophizing Scale: The Pain Catastrophizing Scale (65) consists of 13 items. Participants are asked to reflect on their past painful experiences and indicate the degree to which they exhibit each feeling or thought process presented. The measure consists of three subscales: rumination (eg, 'I keep thinking how much it hurts'); magnification (eg,
'I wonder whether something serious may happen'); and helplessness (eg, 'I feel I can't stand it anymore'). Items are rated on a five-point Likert scale $(0=$ not at all, to $4=$ all the time $)$. Items are summed to give a total score. Empirical evidence has been supportive of the scale's reliability and validity (65-68). Only the total score was used in the present study, with an internal consistency of 0.95 .

The Avoidance-Endurance Questionnaire: The degree to which participants suppress thoughts about pain was assessed using the thought suppression subscale of the Avoidance-Endurance Questionnaire (13). The Avoidance-Endurance Questionnaire has four items relating to thought suppression, and sample items include: 'Don't make such a fuss!' and 'It is important not to let myself go now'. Participants are asked to rank how often they have had the described thought in the past 14 days on a seven-point Likert scale $(0=$ never, to $6=$ always $)$. Psychometric testing by the authors found that the thought suppression scale has adequate criterion-related and content validity (13). The authors used self-reported pain intensity and disability as criterion-related variables and examined correlations between the scale and measures of anxiety, depression and fear-avoidance variables to establish content validity. The scale was not associated with fearavoidance variables and was positively associated with pain intensity and depression. Empirical evidence has also been supportive of the scale's internal consistency $(13,14)$. The Cronbach's alpha coefficient in the present study was 0.81 .

The Oswestry Disability Index: The Oswestry Disability Index (ODI) (69) was used to provide a self-report measure of an individual's pain intensity and pain-related disability. The ODI consists of 10 items: pain intensity, personal care, lifting, walking, sitting, standing, sleeping, sex life, social life and travel. Participants are asked to choose one of six statements corresponding to each item that provides an indication of the intensity of their pain or the severity of their disability. Responses are scored on a 0 to 5 scale, with a score of 5 representing higher levels of pain intensity or disability. For the purposes of the present study, the distances in the walking item of one mile, $1 / 2$ mile and 100 yards were replaced by metric units $(1 \mathrm{~km}, 1 / 2 \mathrm{~km}$ and $100 \mathrm{~m})$. The ODI was developed for low back pain patients (69) and is a commonly used and validated outcome measure in this population (70). However, the items are not specific to back pain, and the questionnaire has also been validated with people with heterogeneous pain (71) and pelvic pain (72). For the purposes of the present study, the pain intensity item was examined separately. The remaining nine items were summed to create a total disability score, which was expressed as a percentage of the total possible score, as per the scoring criteria of the ODI (73). Investigating the influence of individual items and examining the nine disability items in isolation from pain intensity are methods that have been used in previous research (70). The internal consistency rating of the combined disability score using the nine items was 0.74 in the current study.

\section{Statistical analyses}

All statistical analyses were conducted using SPSS GradPack version 18.0 (IBM Corporation, USA) for Windows (Microsoft Corporation, USA). All data were initially assessed for normality, linearity, constant variance and outliers. Preoccupied attachment was identified as being significantly positively skewed and was transformed using a box-cox transformation. The strength and direction of relationships using the transformed variable did not vary substantially from that using the original variable; therefore, results of the untransformed measure of preoccupied attachment are presented in the current study.

Because the present research was exploratory, all possible associations between attachment variables, approaches to activity engagement and proposed mediators were examined as opposed to testing specific hypotheses. A multiple-mediator model was used to examine the direct association between attachment variables and maladaptive approaches to activity engagement, and to test for the mediating role of cognitions. This model is illustrated in Figure 1.

The multiple-mediation model used in the present study enabled the examination of the effect of each mediator while controlling for 
other mediators (specific indirect effects) and the effect of all mediators as a group (total indirect effect) in explaining the relationship between each prototypical measure of attachment and each approach to activity engagement. The relationship between attachment variables and approach to activity engagement, before examining the effects of proposed mediators, is represented by path c. Path c' denotes the relationship between attachment and approach to activity engagement when examined alongside catastrophizing and thought suppression. Path $a$ represents the relationship between attachment variables and the proposed mediators, with path $b$ signifying the significant unique effects of proposed mediators on approach to activity engagement while controlling for attachment variables.

The product of $a_{1}$ and $b_{1}$ quantifies the specific indirect effect of an attachment variable on an approach to activity engagement through catastrophizing, and $a_{2} \times b_{2}$ equates to the specific indirect effect through thought suppression. A total indirect effect can be obtained by adding the two effects $\left(a_{1} b_{1}+a_{2} b_{2}\right)$. c' quantifies the direct effect of an attachment variable on an approach to activity engagement. The total effect of attachment on approach to activity engagement is quantified by $c$ and equates to the direct effect and the sum of the indirect effects $\left(c=c^{\prime}+a_{1} b_{1}+a_{2} b_{2}\right)$.

Bootstrapping was used in the present study to detect significant indirect effects, with Preacher and Hayes' INDIRECT macro for SPSS (74) being used to generate bootstrap CIs for the indirect effects in each mediation model. The macro also provides estimates of all path coefficients in the mediation model and allows for inclusion of covariates. The influence of covariates is considered in all paths in the mediation model. Eight models were produced examining the relationships among each attachment variable and each approach to activity engagement. Age, sex, pain intensity and disability were entered as covariates in each model. Percentile bootstrap tests were chosen. This decision was based on research that indicates percentile bootstrap tests are more accurate in terms of type I errors when the sample size is small $(<500)(75)$. Two thousand bootstrap samples were selected to form the sample distribution of the indirect effect, and $95 \%$ CIs were chosen to draw inferences from the data.

Based on the results generated, the effect of the attachment variable on the approach to activity was determined. If neither the total effect nor the indirect effects were significant, it was ascertained that the attachment variable had no effect on the approach to activity engagement. If the total effect was significant but none of the indirect effects were significant, the attachment variable was determined to have a direct effect on the approach to activity engagement. As recommended by Rucker et al (76), if an indirect effect was significant, the size of the indirect effect as opposed to the significance of path $c$ and ' ' was used to determine whether the mediator fully explained the variance between variables. To provide an indication of the size of the indirect effect, the percentage of the total effect accounted for by the mediator was calculated. This was performed by dividing the unstandardized beta value of path $c^{\prime}$ by the unstandardized beta value of path $c$, then subtracting this value from one $\left(1-c^{\prime} / c\right)$. As a rule of thumb, values $>0.80$ are an indication of complete mediation, whereas lower values suggest that the attachment variable exerts both direct and indirect effects on the approach to activity engagement (77).

Missing data resulted in exclusion of some cases, reducing the power in some models. The smallest number of cases available for any one model was 139 and the amount of data missing for each variable is presented in Tables 1 and 2. An a priori sample size calculation suggested that a minimum of 103 participants would be needed for an $80 \%$ chance to detect medium effect sizes for paths coefficients. In addition, simulation research by Fritz and MacKinnon (78) suggested that a minimum of 78 participants would be required for an $80 \%$ chance to detect an indirect effect with medium effect sizes for paths a and $b$. As such, the current sample was considered to have adequate power. As recommended by Streiner and Norman (79) a correction was not used to account for multiple analyses due to the exploratory nature of the present study.

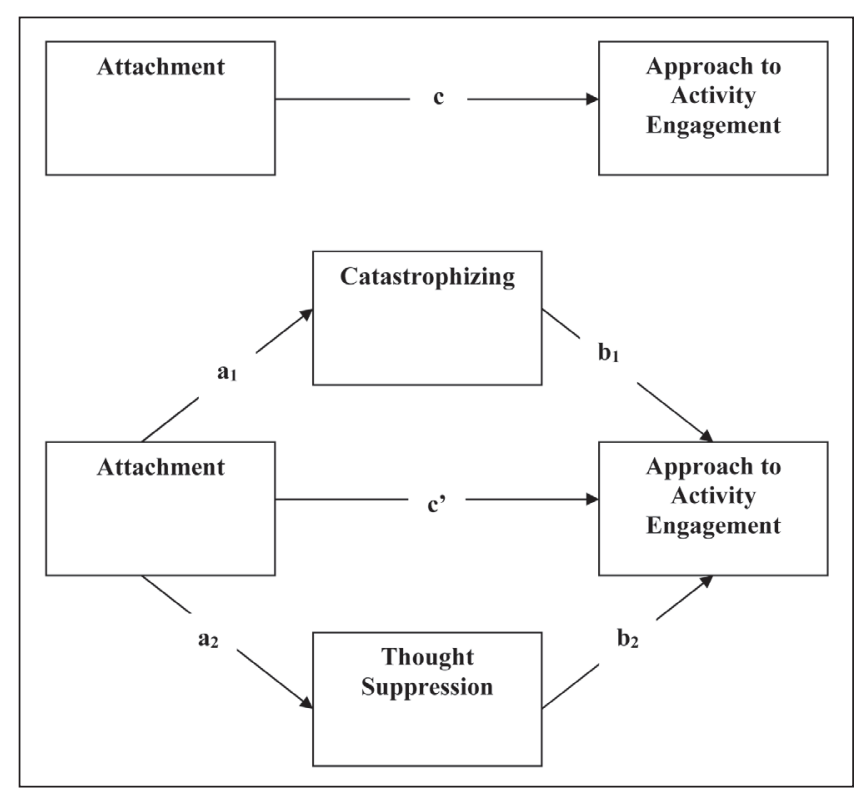

Figure 1) Path diagram illustrating the hypothesized mediating role of cognitions in the relationship between attachment variables and approaches to activity engagement

\section{RESULTS}

Results are presented in Table 3 and detailed in the text below. Table 3 includes the unstandardized regression coefficient for all pathways in the eight mediation models and flags significant pathways. The $95 \%$ bootstrap CI for all specific indirect effects tested, an indication of the size of the significant indirect effects and the determined effect of the attachment variable on the approach to activity is also presented in this table. The text below provides more detailed statistics for significant pathways and the nonsignificant pathways that relate to the study hypotheses, including $t$ values, degrees of freedom and specific $\mathrm{P}$ values. Results below are organized according to hypothesis.

\section{Results relating to secure attachment (hypothesis 1)}

Secure attachment was associated with lower levels of catastrophizing $(\mathrm{B}=-1.11, t(137)=-2.29, \mathrm{P}=0.023)($ path $a)$ and the specific indirect effect of secure attachment on activity avoidance through catastrophizing was significant ( $95 \% \mathrm{CI}-0.68$ to -0.02$)$. Secure attachment was not associated with thought suppression $(B=-0.00, t[137]=-0.05$, $\mathrm{P}=0.96$ ) (path $a$ ), and thought suppression did not influence the relationship between secure attachment and activity avoidance $(95 \% \mathrm{CI}$ -0.105 to 0.062 ). The inclusion of proposed mediators in this model accounted for $99 \%$ of the total relationship between secure attachment and self-reported avoidance behaviour. This suggests that catastrophizing completely mediated the relationship between secure attachment and activity avoidance, with higher levels of secure attachment associated with decreased levels of catastrophizing which, in turn, was linked with decreased avoidance behaviour in accordance with hypothesis 1 . In addition, secure attachment was not a significant predictor of overactivity in path $c(B=0.15, t[138]=0.57$; $\mathrm{P}=0.57$ ), and none of the specific or total indirect effects were significant in this model.

\section{Results relating to preoccupied attachment (hypothesis 2)}

Results supported the second hypothesis. Higher levels of preoccupied attachment predicted higher levels of both overactivity $(B=0.56$, $t[139]=2.00 ; \mathrm{P}=0.047)$ and activity avoidance $(\mathrm{B}=0.74, t[138]=2.29$; $\mathrm{P}=0.024$ ) while controlling for age, sex, disability and pain intensity, as shown by significant total effects in path $c$. In addition, higher levels of preoccupied attachment were associated with higher levels of catastrophizing $(\mathrm{B}=0.25, t[138]=5.06 ; \mathrm{P}=0.002)$ (path $a)$. None of the 
TABLE 3

Mediation analyses exploring the relationships among attachment variables and maladaptive approaches to activity engagement

\begin{tabular}{|c|c|c|c|c|c|c|c|c|c|c|c|c|c|c|}
\hline \multirow[b]{2}{*}{ Model } & \multicolumn{3}{|c|}{ Independent Dependent } & \multicolumn{2}{|c|}{ Path a } & \multicolumn{2}{|c|}{ Path $b$} & \multicolumn{2}{|c|}{ Path $c$} & \multicolumn{2}{|c|}{ Path $c^{\prime}$} & \multirow[b]{2}{*}{$95 \% \mathrm{Cl}$} & \multirow{2}{*}{$\begin{array}{c}\text { Proportion } \\
\text { mediated }\end{array}$} & \multirow[b]{2}{*}{ Effect } \\
\hline & variable & variable & Mediator & B & SE & B & SE & B & SE & B & SE & & & \\
\hline \multirow[t]{2}{*}{1} & Secure & Avoidance & Catastrophizing & $-1.11^{*}$ & 0.48 & $0.26^{* *}$ & 0.05 & -0.29 & -0.29 & -0.00 & 0.27 & -0.68 to -0.02 & $99 \%$ & 1 \\
\hline & & & $\begin{array}{l}\text { Thought } \\
\text { suppression }\end{array}$ & -0.14 & 0.27 & -0.00 & 0.09 & -0.29 & 0.29 & -0.00 & 0.27 & -0.08 to 0.06 & & \\
\hline \multirow[t]{2}{*}{2} & Secure & Overactivity & Catastrophizing & -0.93 & 0.48 & $0.13^{* *}$ & 0.05 & 0.15 & 0.26 & 0.28 & 0.25 & -0.29 to 0.01 & - & NE \\
\hline & & & $\begin{array}{l}\text { Thought } \\
\text { suppression }\end{array}$ & -0.25 & 0.26 & 0.07 & 0.08 & 0.15 & 0.26 & 0.28 & 0.25 & -0.11 to 0.06 & & \\
\hline \multirow[t]{2}{*}{3} & Preoccupied & Avoidance & Catastrophizing & $1.68^{* *}$ & 0.53 & $0.25^{\star *}$ & 0.05 & $0.74^{*}$ & 0.32 & 0.31 & 0.31 & 0.13 to 0.86 & $58 \%$ & $D \& I$ \\
\hline & & & $\begin{array}{l}\text { Thought } \\
\text { suppression }\end{array}$ & -0.00 & 0.30 & -0.00 & 0.08 & $0.74^{*}$ & 0.32 & 0.31 & 0.31 & -0.05 to 0.07 & & \\
\hline \multirow[t]{2}{*}{4} & Preoccupied & Overactivity & Catastrophizing & $1.58^{* *}$ & 0.53 & $0.10^{*}$ & 0.05 & $0.56^{*}$ & 0.28 & 0.40 & 0.28 & -0.00 to 0.37 & - & $\mathrm{D}$ \\
\hline & & & $\begin{array}{l}\text { Thought } \\
\text { suppression }\end{array}$ & 0.06 & 0.30 & 0.09 & 0.08 & $0.56^{*}$ & 0.28 & 0.40 & 0.28 & -0.09 to 0.08 & & \\
\hline \multirow[t]{2}{*}{5} & Dismissing & Avoidance & Catastrophizing & 0.68 & 0.49 & $0.26^{\star *}$ & 0.05 & 0.49 & 0.29 & 0.32 & 0.27 & -0.08 to 0.48 & - & NE \\
\hline & & & $\begin{array}{l}\text { Thought } \\
\text { suppression }\end{array}$ & $0.60^{*}$ & 0.26 & -0.02 & 0.09 & 0.49 & 0.29 & 0.32 & 0.27 & -0.15 to 0.11 & & \\
\hline \multirow[t]{2}{*}{6} & Dismissing & Overactivity & Catastrophizing & 0.78 & 0.48 & $0.11^{*}$ & 0.04 & 0.40 & 0.25 & 0.27 & 0.25 & -0.02 to 0.25 & - & NE \\
\hline & & & $\begin{array}{l}\text { Thought } \\
\text { suppression }\end{array}$ & $0.52^{*}$ & 0.26 & 0.08 & 0.08 & 0.40 & 0.25 & 0.27 & 0.25 & -0.05 to 0.19 & & \\
\hline \multirow[t]{2}{*}{7} & Fearful & Avoidance & Catastrophizing & $1.69^{* *}$ & 0.48 & $0.27^{* *}$ & 0.05 & 0.45 & 0.30 & 0.09 & 0.29 & 0.17 to 0.82 & $80 \%$ & 1 \\
\hline & & & $\begin{array}{l}\text { Thought } \\
\text { suppression }\end{array}$ & 0.32 & 0.27 & -0.01 & 0.09 & 0.45 & 0.30 & 0.09 & 0.29 & -0.08 to 0.09 & & \\
\hline \multirow[t]{2}{*}{8} & Fearful & Overactivity & Catastrophizing & $1.56^{\star \star}$ & 0.47 & $0.09^{*}$ & 0.05 & $0.61^{*}$ & 0.25 & 0.44 & 0.26 & -0.01 to 0.33 & - & $\mathrm{D}$ \\
\hline & & & $\begin{array}{l}\text { Thought } \\
\text { suppression }\end{array}$ & 0.35 & 0.28 & 0.09 & 0.08 & $0.61^{*}$ & 0.25 & 0.44 & 0.26 & -0.04 to 0.13 & & \\
\hline
\end{tabular}

*Significant at the 0.05 level; **Significant at the 0.01 level. B Unstandardized regression coefficients; D \& I Direct and indirect; D Direct only; Effect Determined effect of attachment variable on approach to engagement; I Indirect; NE No effect; Proportion mediated Indication of percentage of the total effect (path c) accounted for by the mediator; $95 \% \mathrm{Cl} 95 \%$ bootstrap Cl for the specific indirect effect

indirect effects were significant in explaining the relationship between preoccupied attachment and overactivity, indicating that preoccupied attachment was directly associated with overactivity. The specific indirect effect of preoccupied attachment on activity avoidance through catastrophizing was significantly different from zero $(95 \% \mathrm{CI}$ 0.133 to 0.863 ). Positive associations between variables indicated that higher levels of preoccupied attachment were associated with increased catastrophizing which, in turn, was associated with increased avoidance behaviour. The proportion of the total effect of preoccupied attachment on activity avoidance accounted for by the inclusion of proposed mediators was $58 \%$. This suggests that preoccupied attachment exerted both a direct and an indirect effect through catastrophizing on activity avoidance.

Results relating to dismissing attachment (hypothesis 3)

Results were mixed in accordance to predictions related to dismissing attachment. Consistent with hypothesis 3, dismissing attachment was a significant predictor of thought suppression $(B=0.60, t[140]=2.32$; $\mathrm{P}=0.022)$ (path $a)$ and was not related to catastrophizing $(\mathrm{B}=0.68$, $t[140]=1.40 ; \mathrm{P}=0.16)$ (path $a)$ or avoidance behaviour $(\mathrm{B}=0.49$, $t[140]=1.67 ; \mathrm{P}=0.10$ ) (path $c$ ). However, in contrast with predictions, dismissing attachment was also not associated with overactivity $(B=0.40, t[141]=1.59 ; P=0.12)$ (path $c)$ and none of the specific or total indirect effects were significant in mediation models that contained dismissing attachment as an independent variable. This suggests that dismissing attachment had no significant association with overactivity or activity avoidance.

Results relating to fearful attachment (hypothesis 4 )

Results supported hypothesis 4. Fearful attachment made a significant contribution to the prediction of overactivity when measured alongside age, sex, disability and pain intensity in path $c(B=0.61$, $t(141)=2.45 ; \mathrm{P}=0.02)$. A positive association was observed between fearful attachment and overactivity, with higher ratings of fearful attachment predictive of more self-reported engagement in overactivity. Fearful attachment was determined to have a direct effect on overactivity because none of the indirect effects were significant in this model. Higher levels of fearful attachment were associated with higher levels of catastrophizing $(\mathrm{B}=1.69, t[138]=3.51 ; \mathrm{P}=0.001)$ (path a) and the specific indirect effect of fearful attachment on activity avoidance through catastrophizing was significantly different from zero (95\% CI 0.168 to 0.818). Fearful attachment was not associated with thought suppression $(\mathrm{B}=0.32, t[138]=1.19 ; \mathrm{P}=0.23)$ (path $a$ ) and the specific indirect effect through thought suppression was not significant in this model ( $95 \%$ CI -0.080 to 0.090 ). The inclusion of proposed mediators in this model accounted for $80 \%$ of the total effect between fearful attachment and activity avoidance, indicating that fearful attachment was only indirectly associated with activity avoidance through catastrophizing. The direction of associations suggests that higher levels of fearful attachment were associated with increased catastrophizing, which, in turn, were linked with increased activity avoidance.

Predicting a combination of overactivity and avoidance behaviour Because preoccupied and fearful attachment were associated with both activity avoidance and overactivity, further analyses were undertaken to determine whether these attachment variables predicted a combination of overactivity and avoidance behaviour. Clinicians have documented observations of a combination of overactivity and activity avoidance manifesting in the same individual with chronic pain $(1,17)$ and a subgroup of individuals with chronic pain reporting higher levels of both overactivity and avoidance has been identified in two studies $(62,80)$. In both studies, this subgroup reported higher levels of pain and disability compared with the high overactivity/low avoidance subgroup and individuals who solely reported high levels of avoidance. 
TABLE 4

Mediation analyses exploring the relationships among attachment variables and a combination of overactivity and avoidance behaviour

\begin{tabular}{|c|c|c|c|c|c|c|c|c|c|c|c|c|c|}
\hline \multirow[b]{2}{*}{ Model } & \multirow{2}{*}{$\begin{array}{c}\text { Independent } \\
\text { variable }\end{array}$} & \multirow[b]{2}{*}{ Mediator } & \multicolumn{2}{|c|}{ Path a } & \multicolumn{2}{|c|}{ Path $b$} & \multicolumn{2}{|c|}{ Path $c$} & \multicolumn{2}{|c|}{ Path $c^{\prime}$} & \multirow[b]{2}{*}{$95 \% \mathrm{Cl}$} & \multirow{2}{*}{$\begin{array}{c}\text { Proportion } \\
\text { mediated }\end{array}$} & \multirow[b]{2}{*}{ Effect } \\
\hline & & & B & SE & B & SE & B & SE & B & SE & & & \\
\hline \multirow[t]{2}{*}{$\overline{1}$} & Preoccupied & Catastrophizing & $1.62^{* *}$ & 0.53 & $0.07^{* *}$ & 0.02 & $0.26^{* *}$ & 0.10 & 0.20 & 0.11 & 0.03 to 0.26 & $31 \%$ & $D \& I$ \\
\hline & & $\begin{array}{l}\text { Thought } \\
\text { suppression }\end{array}$ & 0.04 & 0.30 & $0.07^{*}$ & 0.03 & $0.26^{* *}$ & 0.10 & 0.20 & 0.11 & -0.05 to 0.06 & & \\
\hline \multirow[t]{2}{*}{2} & Fearful & Catastrophizing & $1.66^{* *}$ & 0.49 & $0.07^{* *}$ & 0.02 & $0.20^{*}$ & 0.09 & 0.09 & 0.10 & 0.04 to 0.28 & $59 \%$ & $D \& I$ \\
\hline & & $\begin{array}{l}\text { Thought } \\
\text { suppression }\end{array}$ & 0.21 & 0.27 & 0.06 & 0.03 & $0.20^{*}$ & 0.09 & 0.09 & 0.10 & -0.02 to 0.08 & & \\
\hline
\end{tabular}

*Significant at the 0.05 level; **Significant at the 0.01 level. 95\% Cl 95\% bootstrap Cl or the specific indirect effect; B Unstandardized regression coefficients; $D$ \& I Direct and indirect; Effect Effect of attachment variable on approach to engagement; Proportion mediated Indication of percentage of the total effect (path c) accounted for by the mediator

To determine whether preoccupied and fearful attachment were associated with simultaneously engaging in overactivity and avoidance behaviour, four clusters were created from the confronting and avoidance subscales of the PARQ (62): those high in overactivity and activity avoidance; those high in activity avoidance but low in overactivity; those high in overactivity but low in activity avoidance; and those low in both overactivity and activity avoidance. These clusters were determined on the basis of scores obtained on both the avoidance and confronting subscales. Because this is a six-point scale ( 0 to 5 ), an average score of $\geq 3$ indicated high avoidance (as measured by the avoidance subscale) or high overactivity (as measured by the confronting scale), while an average score $<3$ indicated low levels of avoidance or overactivity. All participants were classified according to the aforementioned clusters. A dichotomous variable was then created to indicate whether participants were high in both avoidance behaviour and overactivity, or belonged to another cluster.

Two mediation models were then produced using Preacher and Hayes' macro (74) to examine both direct and indirect effects of the attachment variables on the high overactivity, high avoidance cluster. Age, sex, disability and pain intensity were again entered as covariates in each model. Because a binary outcome was used in these models, the indirect and total effects were scaled differently. This is because when a variable is used as a predictor in logistic regression, it has a different scale from when it is an outcome variable in linear regression. Thus, $c-c$ ' does not equate to the indirect effect in these models. As such, the scale was made equivalent across equations using procedures described by Mackinnon and Dwyer (81), and Herr (82) before calculation of the indirect effect size using the formula $1-c^{\prime} / c$.

Results of analyses are presented in Table 4. Both preoccupied and fearful attachment were predictive of classification in the high overactivity, high avoidance cluster while controlling for age, sex, disability and pain intensity in path $c\left(B=0.26\right.$, Wald $\chi^{2}[1]=7.09, \mathrm{P}=0.008$; $\mathrm{B}=0.20$, Wald $\left.\chi^{2}[1]=4.78, \mathrm{P}=0.029\right)$. Results suggest that individuals who report higher levels of preoccupied or fearful attachment are more likely to simultaneously report a combination of high levels of overactivity and activity avoidance. In both models, the specific indirect effect through catastrophizing was significant (95\% CI 0.025 to 0.256; $95 \%$ CI 0.038 to 0.275 , respectively) and the specific indirect effect through thought suppression did not influence the relationship between variables $(95 \% \mathrm{CI}-0.04$ to $0.063 ; 95 \% \mathrm{CI}-0.015$ to 0.077 , respectively). The proportion of the total effect of the attachment variables on the high overactivity, high avoidance cluster accounted for by proposed mediators was 31\% (preoccupied model) and 59\% (fearful model). This suggests that both preoccupied and fearful attachment exerted both a direct and indirect effect on membership to the high overactivity, high avoidance cluster.

\section{DISCUSSION}

The present study applied an attachment theory framework to examine the notion that some individuals are inherently more likely to develop maladaptive approaches to activity engagement in chronic pain. Developing a better understanding of how overactivity and activity avoidance develops may lead to improvements in treatment options aimed at preventing and altering these behaviours. Results provided support for most of the hypotheses.

Consistent with hypothesis 1 , higher levels of secure attachment were not associated with overactivity and were indirectly associated with lower levels of activity avoidance through lower levels of catastrophizing. This suggests that individuals who are more securely attached are less likely to experience catastrophizing thoughts about pain, which in turn leads to less avoidance of their daily activities. This result builds on existing evidence linking secure attachment to constructive coping in chronic pain (50).

Results also supported hypothesis 2: higher levels of preoccupied attachment were associated with higher levels of catastrophizing, activity avoidance and overactivity, with the relationship between preoccupied attachment and activity avoidance being mediated by catastrophizing. A subsequent analysis linked preoccupied attachment with a high overactivity, high activity avoidance cluster, suggesting that individuals reporting higher levels of preoccupied attachment simultaneously engage in overactivity and activity avoidance behaviour. As mentioned previously, clinicians have described a combination of overactivity and activity avoidance behaviour simultaneously manifesting in the same individual with chronic pain. These individuals are believed to engage in high levels of activity following the onset of their pain but start to avoid certain pain-provoking activities over time, resulting in the combination behaviour. Empirically, these individuals have been found to be more disabled and report higher levels of pain compared with individuals who only report higher levels of overactivity or avoidance $(62,80)$.

When combined with previous studies that link preoccupied attachment to high levels of productive task engagement in healthy populations (33-38), the direct association between preoccupied attachment and overactivity in the present study supports the idea that overactivity may be the result of enduring premorbid behaviour (as argued by Butler and Moseley [15] and van Houdenhove [16]) and precedes the development of activity avoidance (as per clinical observations). Hazan and Shaver (31) theorized that individuals with higher levels of preoccupied attachment use work as a means to attract attention and approval from others. Following the onset of pain, individuals who identify more with preoccupied attachment may attempt to meet the perceived demands of a partner or loved one by maintaining their premorbid level of engagement in daily activities, resulting in overactivity.

The notion that preoccupied individuals would then begin to avoid certain activities is supported by attachment research. Individuals reporting higher levels of preoccupied attachment have a primary concern of gaining increased emotional and physical closeness to attachment figures in distressing situations (29). The cessation and avoidance of certain activities could serve as a means of increasing and maintaining proximity to attachment figures; for example, one may enlist additional support to complete a household 
chore no longer able to be completed easily. As anticipated, in the present study, the association between preoccupied attachment and activity avoidance was partially mediated by catastrophizing. Those with higher levels of preoccupied attachment are known to intensify emotions that emphasize vulnerability and neediness to elicit caring behaviour from others (29). Pain catastrophizing has been defined as "an exaggerated negative mental set brought to bear during actual or anticipated painful experience" (83). Sullivan et al $(83,84)$ proposed that catastrophizing thought processes relating to pain may externally manifest via exaggerated pain behaviours that serve to maximize proximity, solicit assistance or evoke an empathic response from others in their social environment, otherwise known as the communal coping model of catastrophizing. Higher levels of pain catastrophizing, as measured by the Pain Catastrophizing Scale, has been associated with a longer duration of communicative pain behaviours when an observer is present, and observer inferences of more intense pain in pain-induced experiments involving healthy individuals $(85,86)$. A patient's level of catastrophizing on entering a medical examination has also predicted the interactive dynamics between the patient and the health care provider in a chronic pain sample (87). In this sense, catastrophizing could contribute to the development of activity avoidance behaviour via exaggerated expressions of pain and successful attempts to elicit caring behaviours from others. Individuals with higher levels of preoccupied attachment may continue to engage in high levels of activity, sporadically, to please others, or heighten pain to elicit support from others, resulting in a combination of overactivity and avoidance behaviour.

Results in relation to predictions concerning dismissing attachment were mixed. While higher levels of dismissing attachment were associated with higher levels of thought suppression, which is consistent with earlier work (54), neither dismissing attachment nor thought suppression predicted overactivity. Research involving healthy individuals supports the viewpoint that those with higher levels of dismissing attachment engage in high levels of productive tasks before pain onset $(31,32)$. However, individuals reporting higher levels of dismissing attachment have a primary concern of gaining whatever they need while maintaining self-reliance and distance from attachment figures (21). Thus, following the onset of chronic pain, they may approach activity in a way that would maximize independence, which would involve persisting with activity but not to the point of severe pain aggravation. Indeed, while thought suppression is believed to contribute to the development of overactivity (12), it has only been linked to endurance behaviour (persisting with activity in spite of pain) in a subacute pain sample (14). It may be that while suppressing thoughts about pain enables individuals to persist with activity, it is not the cognitive process responsible for overactivity. Alternatively, issues with measurement validity may have led to the unexpected finding. The measures used to assess overactivity and thought suppression are relatively new measures that have undergone limited validity testing. Both measures do, however, display good psychometric properties based on existing evidence.

As predicted, higher levels of fearful attachment were associated with higher levels of catastrophizing, overactivity and avoidance. Similar to preoccupied attachment, fearful attachment was significantly associated with the high overactivity, high avoidance cluster, suggesting that individuals reporting higher levels of fearful attachment simultaneously engage in overactivity and avoidance behaviour. In the present study, there was a direct association between fearful attachment and overactivity. Research involving healthy samples suggests that fearful attachment is associated with high levels of activity engagement before the onset of a disease (33-38). Fearful individuals are believed to primarily deactivate the attachment system in an attempt to cope with threats $(21,25)$. Following the development of chronic pain, individuals who report higher levels of fearful attachment may continue to engage in high levels of activity and productive tasks to maintain independence and distance themselves from others, explaining the direct relationship observed in the present study. In previous research, fearful attachment has been linked to other deactivation strategies such as a reluctance to seek support or rely on others (88) and lower levels of health care utilization (89) following the onset of an illness/disease.

The relationship between fearful attachment and activity avoidance was fully mediated by catastrophizing. Higher levels of fearful attachment have been linked to higher levels of catastrophizing in two previous chronic pain samples $(43,51)$. It is presently unclear whether catastrophizing represents an excessive focus on negative aspects of the pain experience secondary to poor coping, or a means to elicit support from others and, hence, a strategy to hyperactive the attachment system for individuals with high levels of fearful attachment (89).

In the first instance, individuals who identify more with fearful attachment may avoid certain pain-provoking activities, such as leisure activities causing pain exacerbations, to minimize their distress. These individuals may still engage in what they consider to be essential daily activity - eg, household chores and personal care tasks - as they have previously, to continue to avoid dependence and close relationships with others. This would result in a combination of overactivity and avoidance behaviour. Alternatively, the combination behaviour may be a manifestation of what Simpson and Rholes (30) referred to as a haphazard, chaotic enactment of both hyperactivating (catastrophizing and activity avoidance) and deactivating (overactivity) strategies. In this case, as per the discussion relating to preoccupied attachment, catastrophizing could lead to the development of activity avoidance secondary to exaggerated expressions of pain and successful attempts to elicit support in which loved ones begin performing activities for the person in pain.

Results from experimentally induced pain studies provide support for the former argument. In these studies, individuals with higher levels of fearful attachment reported more pain catastrophizing on selfreport questionnaires, but less pain to the researcher during the experiment, suggesting that catastrophizing may not be a hyperactivation strategy for these individuals $(53,54)$. Meredith et al $(43)$ also found that while both preoccupied and fearful attachment are associated with higher levels of catastrophizing in a chronic pain sample, only fearful attachment was linked to appraising pain as more threatening. This may indicate that catastrophizing is a product of ongoing distress and inability to cope effectively with pain for those identifying more with fearful attachment but not for those with higher levels of preoccupied attachment. Investigating individual differences in the types of activities that are avoided or that result in overactivity may provide further insight.

The results of the present exploratory study should be considered to be preliminary and interpreted with several caveats in mind. The number of statistical tests conducted in the current study increased the chance of type I error and, as such, the results should be treated as hypothesis generating and requiring replication. In addition, although mediation models were investigated to enhance understanding of relationships between variables, the cross-sectional nature of the study limits conclusions regarding causality. Because self-report instruments were used, the variables measured reflect participant's perceptions. Social desirability responding was possible due to the self-report nature of measures and the inclusion of the principal researcher as a member of the multidisciplinary treating team.

Approaches to activity engagement, as measured in the present study, reflected habitual approaches to managing activity (62). Approaches to activity engagement and resultant activity patterns are highly complex, often change over time and can be dependent on situational variables (62). Because the present study only determined the respondents' general tendencies toward activity, future studies should aim to capture this variability. Furthermore, individuals who participated in the study were recruited from a tertiary pain clinic, limiting the ability to generalize findings to individuals with chronic pain in the community who are not seeking active multidisciplinary treatment. 


\section{CONCLUSIONS}

Despite the limitations discussed, the results of the present study offer the first empirical support for associations between insecure attachment and maladaptive approaches to activity engagement in chronic pain. The present study was also the first to investigate the association between attachment and activity engagement following the onset of a disease. While not all a priori hypotheses were supported, the results are theoretically defensible and are consistent with the premise that certain insecure attachment patterns may be a source of vulnerability for the development of disabling activity patterns in chronic pain. The results of the present study support the potential merit in adopting an attachment framework in both the assessment and treatment of pain $(41,50)$. This would enable the identification of certain subgroups of people who may, based on their attachment pattern, be at greater risk for developing disabling approaches to activity and assist in the development of individually tailored treatments based on attachmentinformed understanding of their needs. A number of treatments aimed at increasing attachment security have been developed and detailed in literature $(50,90,91)$. These include therapies that use the therapeutic relationship to foster the development of a secure base such as meaning- and attachment-based intervention (92). In these interventions, the development of a therapeutic secure base serves to facilitate new ways of thinking and feeling about the self, others and relationships (91). Attachment-informed couples therapy (93) and family-based psychotherapeutic approaches (94) have also been described. The aims of these interventions are to increase insight into the impact of past and present relationship interactions, improve communication skills, and promote safe emotional engagement and responsiveness between individuals (91). Given the results of the present study, the incorporation of these treatments may be beneficial in addition to the current cognitive behavioural therapies offered in the contemporary clinical context.

Given the exploratory nature of the current research, the replication of the present study using heterogeneous chronic and subacute pain samples is warranted. Longitudinal studies using primary health care, trauma or orthopedic samples could further increase our understanding of how a combination of overactivity and avoidance behaviour develops by examining the relationships between adult attachment patterns, approach to activity and pain catastrophizing overtime following pain onset. As mentioned previously, investigating individual differences in the types of activities that are avoided or result in overactivity may provide further insight into how catastrophizing mediates the relationship between attachment variables and activity avoidance. The development and evaluation of attachment-based treatments aimed at modifying activity avoidance and overactivity behaviour is also an avenue for future research.

ACKNOWLEDGEMENTS: The authors thank Asad Khan PhD and Peter Baker PhD, from The University of Queensland (Brisbane, Australia), for their assistance with the statistical processes of some parts of this research, as well as the staff and patients of the Professor Tess Cramond Multidisciplinary Pain Centre for their contribution to data collection.

FUNDING: Nicole E Andrews was supported by a Royal Brisbane and Women's Hospital Foundation Scholarship; an OT board of Queensland novice researcher grant; and the Cramond Fellowship in Occupational Therapy and Pain Management at the Royal Brisbane and Women's Hospital (Brisbane, Australia).

\section{REFERENCES}

1. Philips HC. The Psychological Management of Chronic Pain. New York: Springer, 1988.

2. Birkholtz M, Aylwin L, Harman R. Activity pacing in chronic pain management: One aim, but which method? Part one: Introduction and literature review. Br J Occup Ther 2004;67:447-52.

3. Brown CA. Occupational therapists' beliefs regarding treatment options for people with chronic pain. Br J Occup Ther 2002;65:398-404.

4. Torrance N, Smith BH, Elliott AM, et al. Potential pain management programmes in primary care. A UK-wide questionnaire and Delphi survey of experts. Fam Pract 2011;28:41-8.

5. Andrews NE, Strong J, Meredith PJ. Activity pacing, avoidance, endurance, and associations with patient functioning in chronic pain: A systematic review and meta-analysis. Arch Phys Med Rehabil 2012;93:2109-21.e7.

6. Vlaeyen JW, Kole-Snijders AM, Boeren RG, van Eek H. Fear of movement/(re)injury in chronic low back pain and its relation to behavioral performance. Pain 1995;62:363-72.

7. Crowley D, Kendall NA. Development and initial validation of a questionnaire for measuring fear-avoidance associated with pain: The Fear-Avoidance of Pain Scale. J Musculoskelet Pain 1999;7:3-19.

8. Karsdorp PA, Vlaeyen JW. Active avoidance but not activity pacing is associated with disability in fibromyalgia. Pain 2009;147:29-35.

9. McCracken LM, Zayfert C, Gross RT. The pain anxiety symptoms scale: Development and validation of a scale to measure fear of pain. Pain 1992;50:67-73.

10. Martin AL, Halket E, Asmundson GJ, Flora DB, Katz J. Posttraumatic stress symptoms and the diathesis-stress model of chronic pain and disability in patients undergoing major surgery. Clin J Pain 2010;26:518-27.

11. Wong WS, Jensen MP, Mak KH, Tam BK, Fielding R. Preliminary psychometric properties of the Chinese version of the Chronic Pain Coping Inventory (ChCPCI) in a Hong Kong Chinese population. J Pain 2010;11:672-80.

12. Hasenbring MI, Verbunt JA. Fear-avoidance and endurance-related responses to pain: New models of behavior and their consequences for clinical practice. Clin J Pain 2010;26:747-53.

13. Hasenbring MI, Hallner D, Rusu AC. Fear-avoidance- and endurancerelated responses to pain: Development and validation of the Avoidance-Endurance Questionnaire (AEQ). Eur J Pain 2009;13:620-8.
14. Hasenbring MI, Hallner D, Klasen B, Streitlein-Böhme I, Willburger R, Rusche H. Pain-related avoidance versus endurance in primary care patients with subacute back pain: Psychological characteristics and outcome at a 6-month follow-up. Pain 2012;153:211-7.

15. Butler DS, Moseley GL. Explain Pain. Adelaide: Noigroup Publications, 2013

16. van Houdenhove B. Prevalence and psychodynamic interpretation of premorbid hyperactivity in patients with chronic pain. Psychother Psychosom 1986;45:195-200.

17. Nicholas M, Molloy A, Tonkin L, Beeston L. Manage Your Pain. Sydney: ABC Books, 2006.

18. Bowlby J. Attachment and Loss: Vol. I Attachment. New York: Basic Books, 1969.

19. Bowlby J. Attachment and Loss: Vol. II Separation. New York: Basic Books, 1973.

20. Bowlby J. Attachment and Loss: Vol. III Loss. New York: Basic Books, 1980

21. Mikulincer M, Shaver PR. Attachment in Adulthood: Structure, Dynamics, and Change. New York: The Guilford Press, 2007.

22. Wartner UG, Grossmann K, Fremmer-Bombik E, Suess G. Attachment patterns at age six in south Germany: Predictability from infancy and implications for preschool behavior. Child Dev 1994;65:1014-27.

23. Waters E, Merrick S, Treboux D, Crowell J, Albersheim L. Attachment security in infancy and early adulthood: A twenty-year longitudinal study. Child Dev 2000;71:684-9.

24. Hamilton CE. Continuity and discontinuity of attachment from infancy through adolescence. Child Dev 2000;71:690-4.

25. Collins NL, Guichard AC, Ford MB, Feeney BC. Working models of attachment: New developments and emerging themes. In: Rholes WS, Simpson JA, eds. Adult Attachment: Theory, Research, and Clinical Implications. New York: The Guilford Press, 2004:196-239.

26. Bartholomew K, Horowitz LM. Attachment styles among young adults: A test of a four-category model. J Pers Soc Psychol 1991;61:226-44.

27. Feeney JA, Noller P, Hanrahan M. Assessing adult attachment. In: Sperling MB, Berman WH, eds. Attachment in Adults: Clinical and Developmental Perspectives. New York: The Guilford Press, 1994:128-52. 
28. Brennan KA, Clark CL, Shaver PR. Self-report measurement of adult attachment: An integrative overview. In: Simpson JA, Rholes WS, eds. Attachment Theory and Close Relationships. New York: The Guildford Press, 1998:46-76.

29. Maunder RG, Hunter JJ. Assessing patterns of adult attachment in medical patients. Gen Hosp Psychiatry 2009;31:123-30.

30. Simpson JA, Rholes WS. Fearful-avoidance, disorganization, and multiple working models: Some directions for future theory and research. Attach Hum Dev 2002;4:223-9.

31. Hazan C, Shaver PR. Love and work: An attachment-theoretical perspective. J Pers Soc Psychol 1990;59:270-80.

32. Hardy GE, Barkham M. The relationship between interpersonal attachment styles and work difficulties. Hum Rel 1994;47:263-81.

33. Meredith PJ, Poulsen A, Khan A, Henderson J, Castrisos V. The relationship between adult attachment styles and work-related self-perceptions for Australian paediatric occupational therapists. Br J Occup Ther 2011;74:160-7.

34. Ulu IP, Tezer E. Adaptive and maladaptive perfectionism, adult attachment, and big five personality traits. J Psychol 2010;144:327-40.

35. Wei M, Mallinckrodt B, Russell DW, Abraham WT. Maladaptive perfectionism as a mediator and moderator between adult attachment and depressive mood. J Couns Psychol 2004;51:201-12.

36. Rice KG, Lopez FG, Vergara D. Parental/social influences on perfectionism and adult attachment orientations. J Soc Clin Psychol 2005;24:580-605.

37. Andersson P, Perris C. Attachment styles and dysfunctional assumptions in adults. Clin Psychol Psychot 2000;7:47-53.

38. Pines AM. Adult attachment styles and their relationship to burnout: A preliminary, cross-cultural investigation. Work Stress 2004;18:66-80.

39. Kolb LC. Attachment behavior and pain complaints. Psychosomatics 1982;23:413-25.

40. Andreson DJ, Hines RH. Attachment and pain. In: Grzesiak RC, Ciccone DS, eds. Psychosocial Vulnerability to Chronic Pain. New York: Springer Publishing Company, 1994:137-52.

41. Mikail SF, Henderson PR, Tasca GA. An interpersonally based model of chronic pain: An application of attachment theory. Clin Psychol Rev 1994;14:1-16.

42. Davies KA, Macfarlane GJ, McBeth J, Morriss R, Dickens C. Insecure attachment style is associated with chronic widespread pain. Pain 2009;143:200-5.

43. Meredith PJ, Strong J, Feeney JA. Evidence of a relationship between adult attachment variables and appraisals of chronic pain. Pain Res Manag 2005;10:191-200.

44. Diehl M, Elnick AB, Bourbeau LS, Labouvie-Vief G. Adult attachment styles: Their relations to family context and personality. J Pers Soc Psychol 1998;74:1656-69.

45. Mickelson KD, Kessler RC, Shaver PR. Adult attachment in a nationally representative sample. J Pers Soc Psychol 1997;73:1092-106.

46. McWilliams LA, Cox BJ, Enns MW. Impact of adult attachment styles on pain and disability associated with arthritis in a nationally representative sample. Clin J Pain 2000;16:360-4.

47. Rossi P, Di Lorenzo G, Malpezzi MG, et al. Depressive symptoms and insecure attachment as predictors of disability in a clinical population of patients with episodic and chronic migraine. Headache 2005:45:561-70.

48. Andersen TE. Does attachment insecurity affect the outcomes of a multidisciplinary pain management program? The association between attachment insecurity, pain, disability, distress, and the use of opioids. Soc Sci Med 2012;74:1461-8.

49. Meredith PJ, Strong J, Feeney JA. Adult attachment variables predict depression before and after treatment for chronic pain. Eur J Pain 2007;11:164-70.

50. Meredith PJ, Ownsworth T, Strong J. A review of the evidence linking adult attachment theory and chronic pain: Presenting a conceptual model. Clin Psychol Rev 2008;28:407-29.

51. Ciechanowski P, Sullivan M, Jensen M, Romano J, Summers H. The relationship of attachment style to depression, catastrophizing and health care utilization in patients with chronic pain. Pain 2003;104:627-37.

52. Tremblay I, Sullivan MJ. Attachment and pain outcomes in adolescents: The mediating role of pain catastrophizing and anxiety. J Pain 2010;11:160-71.

53. Meredith PJ, Strong J, Feeney JA. The relationship of adult attachment to emotion, catastrophizing, control, threshold and tolerance, in experimentally-induced pain. Pain 2006;120:44-52.
54. Andrews NE, Meredith PJ, Strong J. Adult attachment and reports of pain in experimentally-induced pain. Eur J Pain 2011;15:523-30.

55. Wertli MM, Burgstaller JM, Weiser S, Steurer J, Kofmehl R, Held U. The influence of catastrophizing on treatment outcome in patients with non-specific low back pain: A systematic review. Spine 2014;39:263-73.

56. Ravitz P, Maunder R, Hunter J, Sthankiya B, Lancee W. Adult attachment measures: A 25-year review. J Psychosom Res 2010;69:419-32.

57. Fraley RC, Waller NG. Adult attachment patterns: A test of the typological model. In: Simpson JA, Rholes WS, eds. Attachment Theory and Close Relationships. New York: The Guilford Press, 1998:77-114.

58. Bartholomew K. Self report measures of adult attachment. <www. sfu.ca/psyc/faculty/bartholomew/selfreports.htm $>$ (Accessed on December 20, 2012).

59. Scharfe E, Bartholomew K. Reliability and stability of adult attachment patterns. Pers Relationship 1994;1:23-43.

60. Schmitt DP, Alcalay L, Allensworth M, et al. Patterns and universals of adult romantic attachment across 62 cultural regions: Are models of self and of other pancultural constructs? J Cross Cult Psychol 2004;35:367-402.

61. Herzberg DS, Hammen C, Burge D, Daley SE, Davila J, Lindberg N. Attachment cognitions predict perceived and enacted social support during late adolescence. J Adolescent Res 1999;14:387-404.

62. McCracken LM, Samuel VM. The role of avoidance, pacing, and other activity patterns in chronic pain. Pain 2007;130:119-25.

63. Bergner M, Bobbitt RA, Carter WB, Gilson BS. The Sickness Impact Profile: Development and final revision of a health status measure. Med Care 1981;19:787-805.

64. Nielson WR, Jensen MP, Karsdorp PA, Vlaeyen JW. Activity pacing in chronic pain: Concepts, evidence, and future directions. Clin J Pain 2013;29:461-8.

65. Sullivan MJ, Bishop SR, Pivik J. The Pain Catastrophizing Scale: Development and validation. Psychol Assess 1995;7:524-32.

66. Osman A, Barrios F, Gutierrez P, Kopper B, Merrifield T, Grittmann L. The pain catastrophizing scale: Further psychometric evaluation with adult samples. J Behav Med 2000;23:351-65.

67. Velly AM, Look JO, Carlson C, et al. The effect of catastrophizing and depression on chronic pain: A prospective cohort study of temporomandibular muscle and joint pain disorders. Pain 2011;152:2377-83.

68. Papaioannou M, Skapinakis P, Damigos D, Mavreas V, Broumas G, Palgimesi A. The role of catastrophizing in the prediction of postoperative pain. Pain Med 2009;10:1452-9.

69. Fairbank J, Couper J, Davies JB, O’Brien JP. The Oswestry Low Back Pain Questionnaire. Physiother 1980;66:217-73.

70. Fairbank JCT, Pynsent PB. The Oswestry Disability Index. Spine 2000;25:2940-53.

71. Wittink H, Turk DC, Carr DB, Sukiennik A, Rogers W. Comparison of the redundancy, reliability, and responsiveness to change among SF-36, Oswestry Disability Index, and Multidimensional Pain Inventory. Clin J Pain 2004;20:133-42.

72. Grotle M, Garratt AM, Krogstad Jenssen H, Stuge B. Reliability and construct validity of self-report questionnaires for patients with pelvic girdle pain. Phys Ther 2012;92:111-23.

73. Baker D, Pynsent P, Fairbank J. The Oswestry Disability Index revistited. In: Roland M, Jenner J, eds. Back Pain: New Approaches to Rehabilitation and Education. New York: Manchester University Press, 1989:174-86.

74. Preacher KJ, Hayes AF. Asymptotic and resampling strategies for assessing and comparing indirect effects in multiple mediator models. Behav Res Methods 2008;40:879-91.

75. Fritz MS, Taylor AB, MacKinnon DP. Explanation of two anomalous results in statistical mediation analysis. Multivar Behav Res 2012;47:61-87.

76. Rucker DD, Preacher KJ, Tormala ZL, Petty RE. Mediation analysis in social psychology: Current practices and new recommendations. Soc Personal Psychol Compass 2011;5:359-71.

77. Kenny DA. Mediation. <http://davidakenny.net $/ \mathrm{cm} /$ mediate.htm> (Accessed December 20, 2012).

78. Fritz MS, MacKinnon DP. Required sample size to detect the mediated effect. Psychol Sci 2007;18:233-9.

79. Streiner DL, Norman GR. Correction for multiple testing. Is there a resolution? Chest 2011;140:16-8. 
80. Huijnen IP, Verbunt JA, Peters ML, et al. Differences in activity-related behaviour among patients with chronic low back pain. Eur J Pain 2011;15:748-55.

81. Mackinnon DP, Dwyer JH. Estimating mediated effects in prevention studies. Eval Rev 1993;17:144-58.

82. Herr NR. Mediation with dichotomous outcomes. <www.nrhpsych com/mediation/logmed.html> (Accessed December 7, 2012).

83. Sullivan MJ, Thorn B, Haythornthwaite JA, et al. Theoretical perspectives on the relation between catastrophizing and pain. Clin J Pain 2001;17:52-64.

84. Sullivan MJ, Tripp DA, Santor D. Gender differences in pain and pain behavior: The role of catastrophizing. Cog Ther Res 2000;24:121-34

85. Sullivan MJ, Martel MO, Tripp D, Savard A, Crombez G.

The relation between catastrophizing and the communication of pain experience. Pain 2006;122:282-8.

86. Sullivan MJ, Adams H, Sullivan ME. Communicative dimensions of pain catastrophizing: Social cueing effects on pain behaviour and coping. Pain 2004;107:220-6.

87. Tsui P, Day M, Thorn B, Rubin N, Alexander C, Jones R. The communal coping model of catastrophizing: Patient-health provider interactions. Pain Med 2012;13:66-79.
88. Schmidt S, Nachtigall C, Wuethrich-Martone O, Strauss B. Attachment and coping with chronic disease. J Psychosom Res 2002;53:763-73

89. Ciechanowski PS, Walker EA, Katon WJ, Russo JE. Attachment theory: A model for health care utilization and somatization. Psychosom Med 2002;64:660-7.

90. Goodwin I. The relevance of attachment theory to the philosophy, organization, and practice of adult mental health care. Clin Psychol Rev 2003;23:35-56.

91. Bifulco A, Thomas G. Understanding Adult Attachment in Family Relationships. London: Routledge, 2013.

92. Maunder R, Hunter J. An integrated approach to the formulation and psychotherapy of medically unexplained symptoms: Meaning- and attachment-based intervention. Am J Psychother 2004;58:17-33

93. Johnson SM. Attachment theory: A guide for healing couple relationships. In: Rholes WS, Simpson JA, eds. Adult Attachment: Theory, Research and Clinical Implications. New York: The Guilford Press, 2004:367-87.

94. Dallos R. Attachment narrative therapy: Integrating ideas from narrative and attachment theory in systemic family therapy with eating disorders. J Fam Ther 2004;26:40-65. 


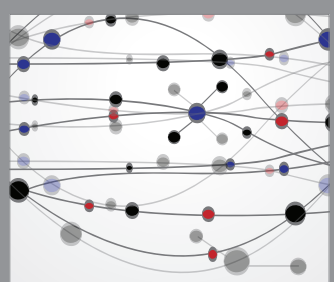

The Scientific World Journal
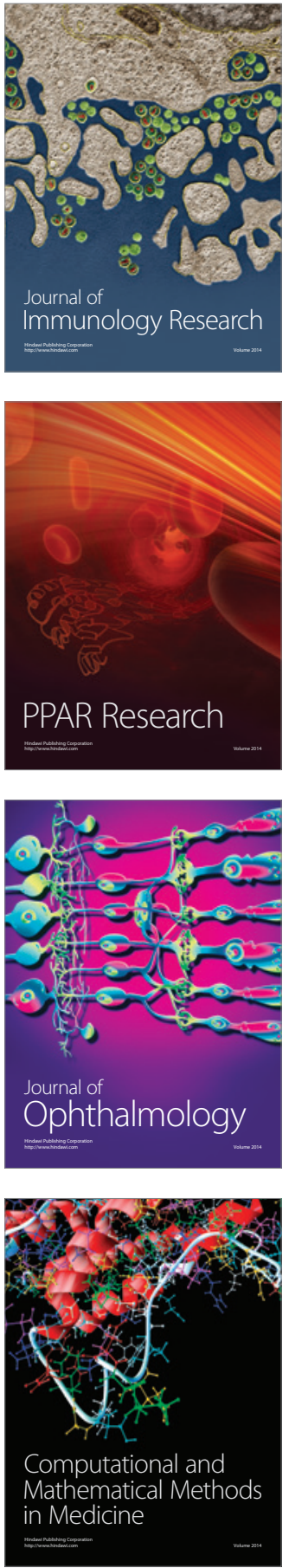

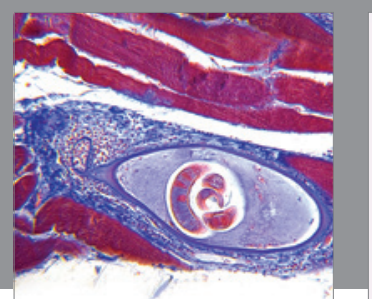

Gastroenterology Research and Practice

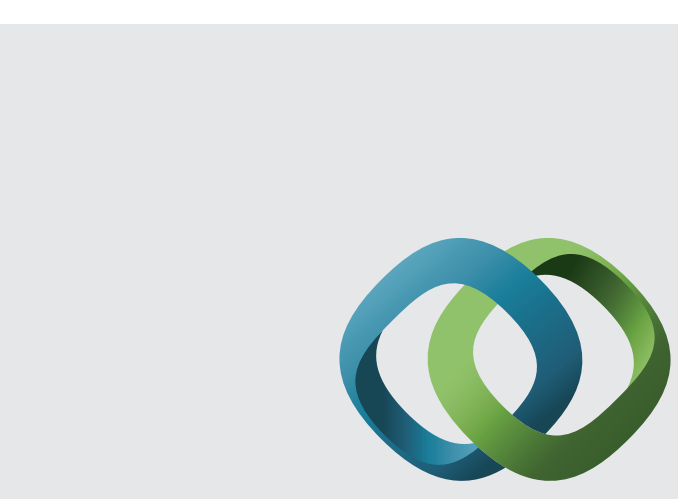

\section{Hindawi}

Submit your manuscripts at

http://www.hindawi.com
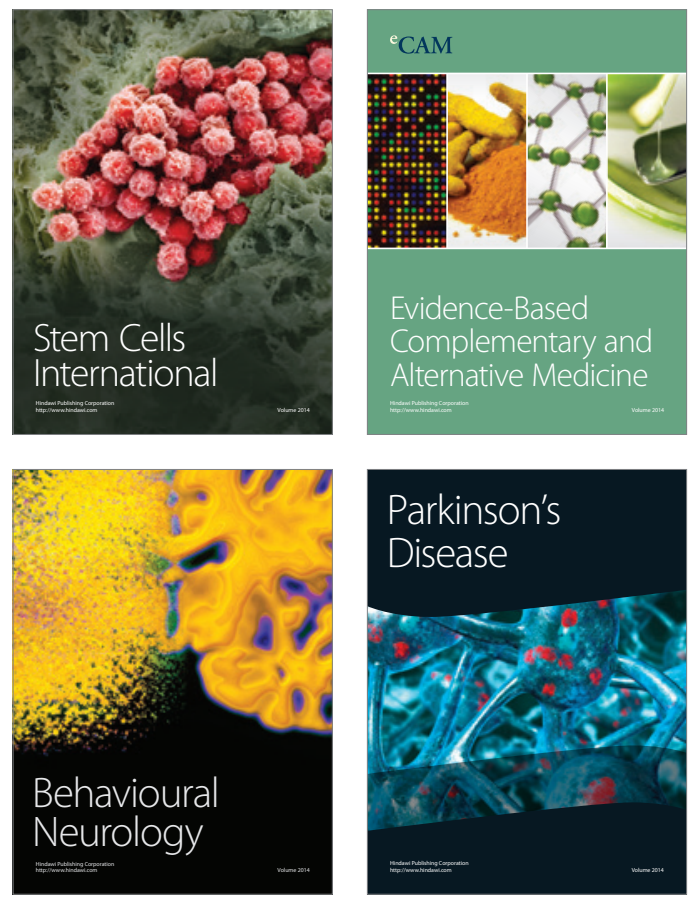
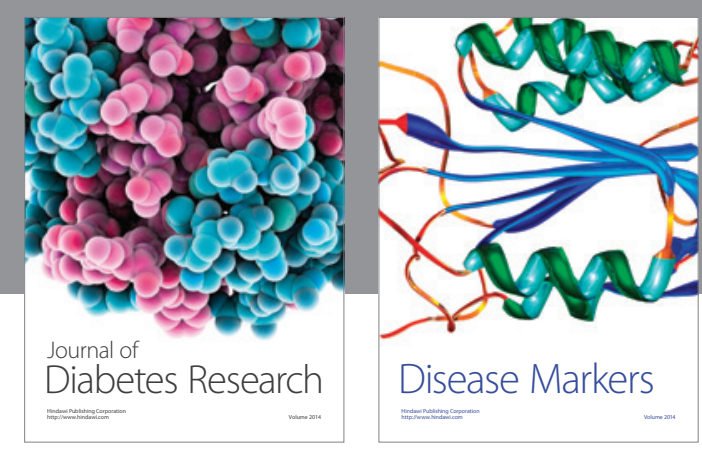

Disease Markers
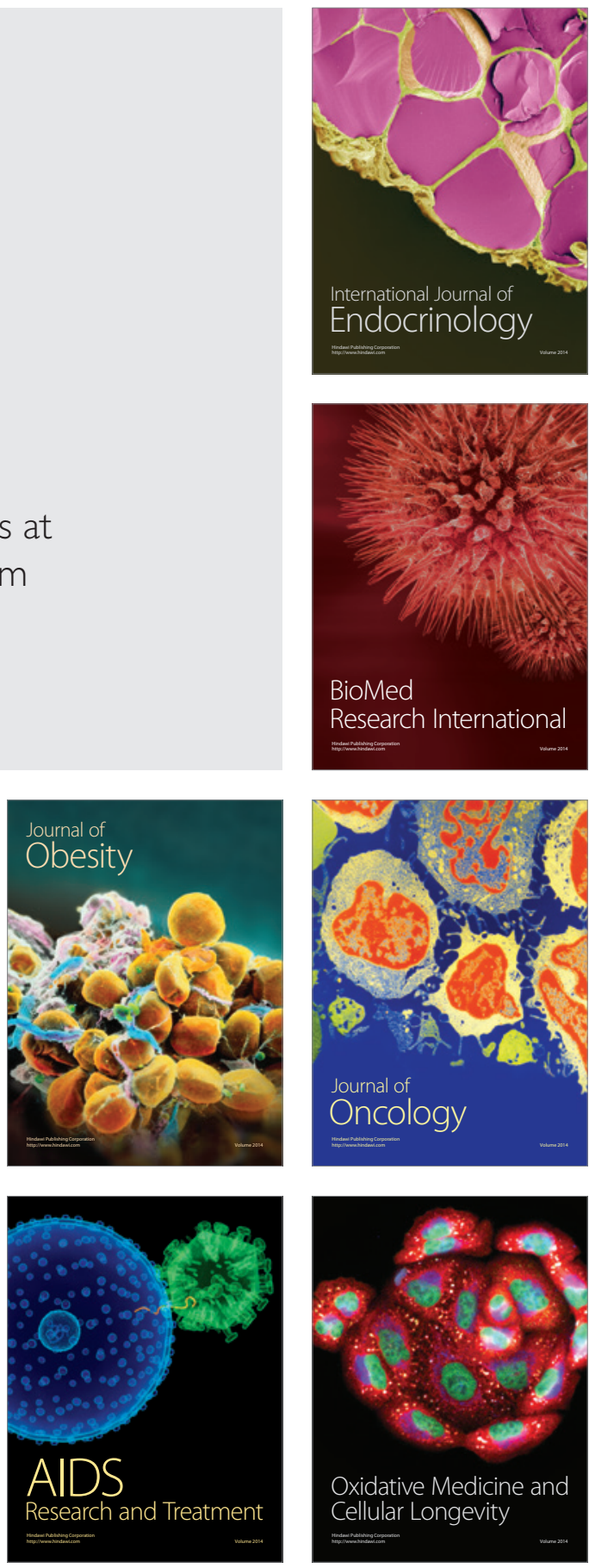